\title{
"CONHECIMENTO TRADICIONAL" E CURRÍCULO MULTICULTURAL: NOTAS COM BASE EM UMA EXPERIÊNCIA COM ESTUDANTES INDÍGENAS KAIOWÁ/GUARANI
}

\author{
"Traditional knowledge" and the multicultural curriculum: \\ notes from an experience with indigenous \\ Kaiowá/Guarani students
}

Maria Aparecida de Souza Perrelli ${ }^{1}$

\begin{abstract}
Resumo: Este artigo situa-se no campo dos estudos culturais que compreendem o currículo escolar como lugar de disputa pela legitimidade de expressão do conhecimento de distintas culturas. Nessa compreensão, e comprometido com o empoderamento do povo indígena Kaiowá/Guarani, este trabalho destinase a conhecer as especificidades dos saberes das sociedades tradicionais e a levantar questões pertinentes à pesquisa e à inserção deste conhecimento no currículo escolar. Os dados foram obtidos com base em levantamento bibliográfico e por meio de depoimentos de estudantes do Curso de Formação de Professores Indígenas Kaiowá/Guarani de Mato Grosso do Sul. O texto traz uma breve apresentação desse povo indígena e da sua luta pela escola específica e intercultural. Caracteriza o conhecimento tradicional (formas de aquisição, distribuição e transmissão) e remete a discussões que argumentam a favor de um currículo escolar aberto aos conhecimentos de culturas historicamente silenciadas.

Palavras-chave: Conhecimento tradicional. Conhecimento indígena. Multiculturalismo. Kaiowá/Guarani.
\end{abstract}

\begin{abstract}
This article is positioned in the field of cultural studies that includes the school curriculum as a place of disputed legitimacy for the expression of the knowledge of different cultures. Based on this theory, and committed to the empowerment of indigenous Kaiowá/Guarani people, this work aims to understand the specific knowledge of traditional societies and raise issues that are relevant to research and the place of such knowledge in the school curriculum. The data were obtained from bibliographical research and through testimonials from students on the Course for Indigenous Kaiowá/Guarani Teachers of the Mato Grosso do Sul. This text provides a brief overview of indigenous people and their struggle for a schooling that is specific and intercultural. Also, it features traditional knowledge (forms of acquisition, distribution and transmission) and refers to discussions which sustain a school curriculum open to the knowledge of cultures which are historically silenced.
\end{abstract}

Keywords: Traditional knowledge. Indigenous knowledge. Multiculturalism. Kaiowá/Guarani.

${ }^{1}$ Bióloga. Doutorado em Educação para a Ciência. Docente, Curso de Biologia, Universidade Católica Dom Bosco (UCDB). Campo Grande, MS. <cidaperrelli@yahoo.com.br>

Rua Euclides da Cunha, 1674

Bairro Santa Fé - Campo Grande, MS

79.021-200 


\section{$O$ contexto da pesquisa}

Uma das lições que podemos aprender com os Estudos Culturais é que as práticas fazem sentido e só podem ser compreendidas no contexto, isto é, nas especificidades históricas e culturais em que são geradas. A pesquisa científica, no seio desses Estudos, é concebida como uma prática histórica e culturalmente situada. Admitindo essa concepção, importa dar visibilidade ao contexto em que a pesquisa foi gerada, a fim de que os seus resultados possam ser compreendidos à luz e em articulação com o momento histórico da sua produção.

Sob essa orientação, inicio dizendo que as preocupações que deram origem a este estudo estão localizadas no tempo do meu encontro com alunos indígenas do Projeto Ara Verá - curso de nível médio voltado à formação de professores kaiowá/guarani de Mato Grosso do Sul. Desde então, tenho sido desafiada a escutar esses alunos, a atribuir significado e sentido aos seus conhecimentos e a compreender um léxico silenciado pelo colonizador.

Quem são os alunos Kaiowá/Guarani que estão me ensinando a dialogar com lógicas distintas das minhas? Por que querem se formar professores?

Os Kaiowá/Guarani de Mato Grosso do Sul viviam em um território amplo e fértil, ocupando uma área de aproximadamente $40.000 \mathrm{~km}^{2}$, dividida ao meio pela fronteira Brasil/ Paraguai. Os que sobreviveram a uma história de assassinato, morte por epidemias, expulsão e ocupação de seu território por fazendeiros e empresas (BRAND, 1997) somam, na atualidade, cerca de 30.000 pessoas, a maioria, crianças e jovens, vivendo confinada em 26 pequenas áreas descontínuas na região sul do Estado.

O confinamento territorial teve, como conseqüências: a desorganização social dessa população, a desconstrução de seus laços familiares, além da grande pressão ambiental que comprometeu a mata nativa, a fauna, os rios, o solo, e atingiu severamente as formas tradicionais de subsistência (BRAND, 1997), os modos de aquisição e transmissão de conhecimentos relacionados com a sobrevivência e a formação da personalidade, enfim, afetou a sua cultura, o seu modo de ser (GRÜNBERG, 2002).

Apesar de todos esses problemas, os Kaiowá/Guarani vêm demonstrando uma enorme capacidade de resistência, e cada vez mais têm se engajado em movimentos e ações destinados à recuperação de sua autonomia e autodeterminação. Nos últimos anos, vê-se um esforço organizado com objetivo de reaver seus espaços tradicionais e criar novas formas de sustentabilidade. Os Kaiowá/Guarani querem incorporar conhecimentos e tecnologias do mundo dos brancos e afiná-las com o seu modo de ser e viver, com sua forma de organização política, social e econômica.

Um dos resultados desse engajamento, alinhado com movimentos internacionais e nacionais de luta pelo direito à diferença, é a conquista da escola indígena específica, bilíngüe e intercultural, já reconhecida pela Constituição Federal. A escola indígena, concebida como espaço de pesquisar, ensinar e aprender as suas próprias tradições, é também lugar de acesso aos conhecimentos produzidos por outras sociedades tradicionais e pela ciência ocidental. Tem-se a expectativa de que, dessa forma, a escola contribua para o empoderamento dos povos indígenas e, assim, favoreça a construção do diálogo com as outras culturas.

Tenho estado ao lado dos Kaiowá/Guarani no processo de construção da escola que quer legitimar suas lógicas, seus conhecimentos e estilos de aprendizagem. Minha participação iniciou-se em 1999, quando comecei a trabalhar no Projeto Ara Verá como docente da disciplina Ciências Naturais. Estou também engajada, desde 2006, em outro projeto, o Teko Arandu - curso superior indígena da Universidade Federal da Grande Dourados/UFGD - 
fruto de mais uma luta do povo Kaiowá/Guarani. Nesses lugares fui descobrindo meus préconceitos e fazendo um duro exercício de revisão das minhas concepções sobre escola, currículo e os saberes das sociedades sem escrita.

Os Estudos Culturais, de visão pós-crítica e pós-colonial, têm me auxiliado nessa caminhada. Por meio deles, passei a compreender: (1) o processo de colonização e as relações de poder como causas do monoculturalismo do currículo, (2) a identidade e a diferença como construções históricas, (3) a escola como lugar de produção de identidades e diferenças, (4) o conhecimento e o currículo como artefatos que expressam significados construídos social e culturalmente a partir de relações de poder, (5) a abertura do currículo a outras expressões culturais, a outros tipos de conhecimentos e de estilos de ensino e aprendizagem, como instrumento de empoderamento das culturas silenciadas, (6) a interculturalidade como algo que não se reduz à relação respeitosa entre pessoas de culturas diferentes; antes, é uma relação desejada e deliberada, na qual ambas as culturas se influenciam e se modificam, é uma resposta à necessidade de convivência entre distintas culturas.

Com essas orientações, passei a compreender os cursos de formação de professores indígenas, nos quais atuo (Projetos Ara Verá e Teko Arandu), como lugares de construção de contextos de influências entre pessoas que têm diferentes histórias de vida, modos próprios de ser, de interpretar o mundo e de produzir conhecimentos. Lugares e tempos de aproximação, de se dar a conhecer e constituir experiência de (trans)formação recíproca.

A redação deste artigo expressa uma parcela do esforço que venho fazendo nesse sentido. Procurei sistematizar aqui algo do que tenho visto, ouvido e lido acerca dos modos de conhecer diferentes dos meus - os saberes das sociedades tradicionais. Entendo que, dessa forma, expresso o desejo de me aproximar dos alunos Kaiowá/Guarani e de (trans)formarme nesse movimento. Com essa intenção, este texto faz uma abordagem de caráter exploratório a respeito do "conhecimento tradicional", buscando mostrar a polissemia do termo e as características distintivas desse conhecimento (modos de aquisição, distribuição e transmissão). Em seguida, faz algumas anotações pertinentes à pesquisa e à inserção do conhecimento tradicional no currículo escolar. O estudo baseou-se em dados obtidos a partir de levantamento bibliográfico e, também, em depoimentos de índios Kaiowá/Guarani, em especial, de alunos do Projeto Ara Verá. Os depoimentos foram colhidos nos anos de 2000 a 2006, no decorrer das aulas de Ciências Naturais, em momentos informais e, ainda, por ocasião de visitas às Aldeias Kaiowá/Guarani de Mato Grosso do Sul. Sempre que possível, as falas foram gravadas em fita $\mathrm{K}-7$.

\section{“Conhecimento tradicional": notas sobre a polissemia do termo}

Ao conceber a existência de um tipo particular de conhecimento dito "tradicional", e ao associá-lo a uma determinada população, coloca-se a necessidade de explicitar o que se entende por "tradicional" e por "população tradicional", uma vez que não há definições universalmente aceitas para ambos os termos.

A palavra "tradição" é freqüentemente associada às idéias de antigüidade e de imutabilidade. Analogamente, o termo "tradicional", quando referido a um tipo de conhecimento, vem revestido de uma conotação de imobilidade histórica ou de atraso em relação a outros conhecimentos (LITTLE, 2002). Quando esse termo é associado a uma determinada população, esta também é percebida como atrasada e imutável, isto é, como um grupo de pessoas 
que recusa todo tipo de compromisso com uma outra cultura, dita moderna (ROUÉ, 2000). O tradicional, assim concebido, seria estático, coletivo e integrado, em oposição à nossa ciência que seria inovadora, individual e fragmentária (SÁEZ, 2001). Tal visão, herdada da antropologia clássica, admite que a mudança e a recriação seriam características exclusivas da civilização ocidental (DIEGUES, 2000), e reflete uma percepção ingênua e também dicotômica a respeito da cultura, pois admite, de um lado, a idéia de modernidade - onde tudo se transforma - e, de outro, a tradição - onde tudo permanece estático (ROUÉ, 2000).

Tais equívocos podem acarretar intolerância para com as populações ditas tradicionais, uma vez que, dentro dessa lógica, tende-se a não se reconhecer como "tradicional" aquele que abandona ou recria seus costumes (ROUÉ, 2000). Em outras palavras, tais visões deturpadas conduzem ao entendimento de que a recriação de práticas pelas sociedades tradicionais implica a sua não legitimidade identitária (DIEGUES, ARRUDA, 2001), posto que se considera "autêntico" [leia-se puro, tradicional, legítimo] apenas o conhecimento e/ou a população que não se modifica por influência dos produtos da modernidade (ROUÉ, 2000).

Contrariando a idéia que associa tradição à antigüidade, à conservação cultural, à imutabilidade ou ao atraso, Sahlins (1997), no contexto das discussões da antropologia atual, defende que as tradições se mantêm e se atualizam mediante uma constante dinâmica de transformação. E é essa forma de ver a cultura - como dinâmica e processual - que, de acordo com Cunha (1999), favorece a compreensão de que a riqueza e a força do "tradicional" residem, justamente, na sua constante capacidade de renovação, produção e reprodução, isto é, na sua possibilidade de desaparecimento, de descoberta e redescoberta, e não na pretensa pureza/autenticidade decorrente da ficção da imutabilidade.

A literatura utiliza diferentes termos para referenciar o conhecimento dito tradicional. Cada um deles expressa o modo como os autores vêem ou concebem esse conhecimento. $\mathrm{Na}$ literatura de língua inglesa podem ser identificados termos como: Indigenous Knowledge/IK, Indigenous Technical Knowledge/ITK, Ethnoecology, Local Knowledge, Folk Knowledge, Traditional Knowledge, Traditional Environmental (ou Ecological) Knowledge/TEK, People's Science, Native/Aboriginal/Tribal Knowledge (ELLEN, HARRIS, 1996), Indigenous Knowledge System/IKS (POSEY, 1997). Entre os termos mais utilizados por pesquisadores e, também, por organizações internacionais envolvidas com a questão dos conhecimentos tradicionais (como a IUCN, UNESCO), estão as siglas TEK/Traditional Ecological Knowledge (ROUÉ, 2000) e, ainda, IK/Indigenous Knowledge. TEK é mais usado para descrever os aspectos desse conhecimento relacionados à preservação do ambiente. Quando se refere à gestão desses saberes, a denominação utilizada preferencialmente é TEKMS/Traditional Ecological Knowledge and Management Systems (ROUÉ, 2000; POSEY, 1997). A literatura de língua francesa utiliza termos como "savoir" ou "connaissance" seguidos de uma das expressões: "traditionelle", "indigène", "indigène traditionelle", "autochtone" ou "local".

Em português, os termos mais usados são "conhecimento tradicional" ou "saber tradicional". Podem ser encontradas, também, as denominações "conhecimento autóctone" e "conhecimento (ou saber) local", "etnociência" (e suas variantes específicas etnozoologia, etnobotânica, etnoecologia, etnomatemática etc.) - termo este que conquistou, nas últimas décadas, um certo espaço no campo das pesquisas em ciências naturais. Quando se faz referência especificamente às sociedades indígenas, observa-se a utilização dos termos "ciência indígena" ou "cultura indígena".

Há uma certa confusão em relação ao termo "tradicional", decorrente da forma como é expresso e traduzido. Por exemplo, o termo "indigenous", do inglês, é usado em 
diversos documentos oficiais (do Banco Mundial e da International Union for Conservation of Nature and Natural Ressources Conservation/IUNC, dentre outros) com o sentido de "tradicional" quando associado a uma determinada população, mas não quer dizer, necessariamente, "indígenas", no sentido étnico e tribal.

Ellen e Harris (1996) fazem ponderações acerca do uso de alguns dos termos mencionados: (1) o uso do termo "indígena" parece não ser muito útil para descrever um tipo particular de conhecimento, pois é ambíguo, tem caráter conflitivo e é moralmente carregado; (2) "nativo" e "aborígine" possuem conotações similares; (3) "tribal" é restritivo e confunde uma condição política com um tipo de conhecimento; (4) "folk" e "tradicional" são termos menos carregados moralmente, mas "folk" pode ter outras conotações; (5) o termo "tradicional" parece ter mais credibilidade e está entre as maneiras mais comuns de se referir a um tipo particular de conhecimento; (6) o termo "população" parece ter pouco compromisso com a historicidade que confere diferenças culturais a um determinado grupo de pessoas; (7) e a denominação "povo" é uma categoria atrelada à lógica do Estado-Nação.

A categoria "sociedade", quando remete ao grupo de pessoas com modos próprios de produção de conhecimento, parece ser a mais aceita na atualidade, e é adotada pelo Relatório "Biodiversidade e Comunidades Tradicionais no Brasil". O Relatório define "sociedades tradicionais" como "grupos humanos culturalmente diferenciados que, historicamente, reproduzem seu modo de vida, de forma mais ou menos isolada, com base em modos de cooperação social e formas especificas de relações com a natureza, caracterizados tradicionalmente pelo manejo sustentado do meio ambiente" (DIEGUES, ARRUDA, 2001, p. 22). Essa concepção se aplica a "povos indígenas e a segmentos da população nacional que desenvolveram modos particulares de existência, adaptados a nichos ecológicos específicos [tais como caiçaras, quilombolas, grupos extrativistas etc]" (p. 23).

Ainda sobre a polissemia, cabe mencionar o cuidado que se deve ter com as possíveis distinções entre os termos "saber" e "conhecimento". Há autores que utilizam ambos os termos indistintamente, mas há outros que estabelecem diferenciações entre eles. Nem sempre, porém, isso está explicitado nos textos, o que pode gerar distorções de interpretação caso se leia a obra isolada do contexto (teórico, filosófico, semântico etc) de sua produção.

Tendo em mente essas ponderações, e sem pretender esgotar o assunto, adotarei neste texto, preferencialmente, os termos "conhecimento tradicional" e "sociedades tradicionais". Sob esses rótulos, farei referência a algumas características comuns aos conhecimentos produzidos pelos Kaiowá/Guarani e por outras sociedades tradicionais indígenas e não-indígenas.

\section{Uma caracterização dos "conhecimentos tradicionais"}

Tomarei duas referências como ponto de partida para levantar alguns aspectos que compõem um conjunto de particularidades do conhecimento tradicional. Uma delas é a definição sugerida por Diegues (2000, p. 30), para quem o "conhecimento tradicional [é] o saber e o saber-fazer a respeito do mundo natural e sobrenatural, gerados no âmbito da sociedade não urbano/industrial e transmitidos oralmente de geração em geração" (grifo nosso). A outra referência, uma fala de Otoniel Benites, índio Kaiowá/Guarani, ex-aluno do Projeto Ara Verá, traz mais elementos que podem caracterizar esse conhecimento: 
"[...] três coisas são importantes: a língua (o oral), a confiança e o respeito. O conbecimento tradicional [...] sempre foi oral e prático. Na escrita, ele se perde. Nosso conbecimento produz muita coisa de valor: remédio, familia, ensina nós a ouvir. Meu pai falava muito em respeito. Eu confiava nele. Assim é a nossa pedagogia. Começa aí. É oralmente, passado pela família. A metodologia é essa: oral. Para alcançar esse respeito, confiança, esses valores eram transmitidos pela familia, na hora de dormir [...] também na hora do chimarrão, do tereré, manhã ou noite, ai passava a educação. Nenbum conhecimento é assim de passado por acaso. [...] Como eles avaliavam que deu certo? Se eu aprendi? Fazendo roça, pescando, na festa, no canto, nas nossas práticas, no modo de falar, no modo de vestir, no modo de ser"2 (grifos meus).

Pode-se extrair, do conteúdo das citações destacadas, alguns atributos do "conhecimento tradicional": (1) a dinâmica e a organização das sociedades nas quais é gerado, experimentado, modificado e transmitido; (2) a sua geração em um determinado grupo e local; (3) a sua relação com o natural e sobrenatural; (4) a oralidade como forma de transmissão; (5) o engajamento prático; (6) a confiança nele depositada pela sociedade que o produziu; (7) a exigência intelectual para saber e fazer; (8) as peculiaridades do processo de produção desse tipo de conhecimento, isto é, os modos como ocorrem a sua aquisição, ensinamento e transmissão. Importa explorar um pouco mais cada um desses aspectos tomando como referência alguns estudos sobre a questão.

Há um certo consenso, entre os pesquisadores, de que os conhecimentos tradicionais são adquiridos em conseqüência de engajamento prático e diário (ELLEN, HARRIS, 1996) nos diferentes campos da vida social nos quais as sociedades tradicionais tomam as suas decisões sobre o seu cotidiano (GALLOIS, 2004). É no dia-a-dia, e ao longo de muitas gerações, que os conhecimentos são repetidos, reforçados, modificados e, até mesmo, abandonados em decorrência das mudanças de condições de sua produção e/ou aplicação e transmissão (ELLEN, HARRIS, 1996).

Entretanto, afirmar o empirismo como uma das condições de aquisição do conhecimento tradicional não significa dizer que há uma espécie de 'naturalidade' desse conhecimento, como se este fosse uma continuidade do homem primitivo com a natureza, ou como se fosse uma forma de engajamento prático instintivo e inconsciente (SÁEZ, 1998). Ao contrário, as populações tradicionais não só vivem e convivem com o ambiente natural, como também pensam sobre ele e elaboram categorias próprias com as quais nomeiam, classificam, ordenam e experimentam a sua eficácia nos planos prático, simbólico e espiritual (DIEGUES, ARRUDA, 2001).

Um dos clássicos que inspirou boa parte do que se pensa hoje a respeito do empirismo associado ao conhecimento tradicional foi o "Pensamento Selvagem", de Lévi-Strauss (1989). Nessa obra, o autor conclui, com base em um longo período de observações em campo, que o conhecimento dos povos indígenas "supõe séculos de observação ativa e metódica, hipóteses ousadas e controladas, a fim de rejeitá-las ou confirmá-las através de experiências incansavelmente repetidas" (LÉVI-STRAUSS, 1989, p. 29). Sendo assim, o conhecimento indígena, como qualquer outro conhecimento, corresponderia, antes, "a exigências intelec-

${ }^{2}$ Fala de Otoniel Benites proferida em Mesa-Redonda no Colóquio “Educação Indígena”, promovido pelo Programa de Mestrado em Educação, da UCDB, 2004. 
tuais ao invés de satisfazer às necessidades" (p. 24, grifo meu), pois é fruto de "uma curiosidade assídua e sempre alerta, uma vontade de conhecer pelo prazer de conhecer, pois apenas uma pequena fração das observações e experiências [...] podia fornecer resultados práticos e imediatamente utilizáveis" (p. 30).

Explorando um pouco mais essa idéia, com base nas falas de indígenas Kaiowá/ Guarani, pode-se perceber que o seu engajamento nas atividades práticas diárias produz um tipo de conhecimento que não separa o ambiente natural do social e espiritual. A fala de um dos anciãos da Aldeia Te'ýikue, ao explicar a organização do calendário das atividades de subsistência, permite fazer essa observação:

"O canto do curiango tem o mesmo ritmo do seu nome, na hora que ele canta dá pra saber que é ele; ele reproduz no mês de agosto, setembro, outubro, até metade de novembro; quando ouve o curiango, lembra do calendário; chega essa data, esse mês, o que plantava já começa a dá flor; se canta, Nanderu tá mostrando que já pode plantar."

Também os mais jovens mantêm os seus conhecimentos inseridos numa rede de relações entre o mundo físico, social e espiritual. As falas dos alunos indígenas a respeito da saúde são ilustrativas: "menina até 13 anos não podem comer capivara; após essa idade deve consultar o cacique antes de comer, às vezes tem que benzer a carne antes de ser comida"; "mocinhas não devem comer carne de veado mateiro porque podem ter hemorragia"; "a desnutrição infantil éporque as mães de hoje desmamam as crianças muito cedo, não respeitam as regras de alimentação, a benção dos alimentos, os alimentos proibidos".

Apesar de a prática diária e o prazer de conhecer instigarem a produção do conhecimento tradicional, existem outras vias pelas quais esse conhecimento é produzido, e estas são tão importantes quanto o empirismo. Os alunos Kaiowá/Guarani falam a respeito. Há conhecimentos que "nascem com as pessoas" e há outros que "são revelados e comunicados em sonhos". Segundo eles, "alguns indios, quando nascem, já vêm com o conbecimento, mas só descobrem quando já crescidos, isto é, com a ajuda dos pais". O ambiente familiar é preparado para receber um filho dotado de conhecimentos especiais ("a familia já sabe que a criança que vier a nascer será um cacique, mas a criança já é preparada no ventre da mãe"). Os especialistas (os caciques, rezadores) têm conexão direta com o mundo espiritual e recebem informações que serão utilizadas em benefício da comunidade ("ele já traz um conhecimento através da reza, é o nosso Deus que revela a visão de como ser cientista para o cacique, por isso que são os mais sábios; o sonho ensina qual o lugar do remédio certo").

A literatura faz menção a outras formas de obtenção do conhecimento envolvendo a conexão com o mundo espiritual. Segundo Posey (1997), os indígenas afirmam que o conhecimento pode vir de espíritos ancestrais, aos quais têm acesso por meio de visões e de sonhos. Moreira (2004) acrescenta que o conhecimento pode ser adquirido por meio de revelações, insights, transe xamânico e experiências oníricas.

Qualquer que seja a forma de produção ou aquisição (revelações, visões, engajamento prático cotidiano), é preciso reconhecer que o conhecimento tradicional é fruto de uma lógica complexa, que envolve processos sofisticados de construção, impensáveis sem uma atividade intelectual consciente. Baseado nisso, Sáez (2001) conclui que seria apropriado dizer que o empirismo dos conhecimentos tradicionais se desenvolve no seio de uma teoria e de um método. O autor faz a seguinte colocação: para admitir essa idéia, basta reconhecer que outros sistemas de pensamento e ação, distantes do nosso padrão epistemológico, podem ser capazes de levar à produção de conhecimentos. Diegues e Arruda (2001) também vão nessa direção. Para esses autores, os conhecimentos tradicionais não são uma espécie de estágio anterior ao 
Perrelli, M. A. S.

conhecimento científico, um proto-conhecimento ou um conhecimento pré-lógico; são, sim, conhecimentos fundados em lógicas distintas daquela que denominamos ciência ocidental.

Como circulam os conhecimentos tradicionais adquiridos?

Os canais ou mecanismos de transmissão/aquisição são diversos, e nem sempre se pode associar um determinado conhecimento a um único canal. São exemplos de canais de transmissão/aquisição: a troca, a compra, a conquista por meio de disputas, a aliança matrimonial. Pode ser importante também a transmissão horizontal, em forma de folclore infantil (SÁEZ, 1998). Há ensinamentos veiculados no âmbito familiar (os exemplos, as experiências) e outros no coletivo (os diagnósticos, as tomadas de decisão), mas essa divisão é fluida, pois há situações de intersecção entre um e outro canal (GALLOIS, 2004). Sabe-se que esses conhecimentos podem ser oferecidos ou requeridos.

A distribuição do conhecimento tradicional entre os membros da comunidade é segmentada e assimétrica, isto é, aquilo que é dado a conhecer aos membros da coletividade não é igualmente distribuído, variando segundo critérios como gênero, idade, função social (SÁEZ, 2001; ELLEN, HARRIS, 1996), laços de parentesco, preferências individuais (SÁEZ, 1998), além da continuidade ou não das gerações. Portanto, o conhecimento tradicional não existe, em sua totalidade, em nenhum lugar ou indivíduo, embora possa haver a figura do especialista, o que não é o mesmo que dizer que existem detentores da totalidade do conhecimento. Nas sociedades indígenas em que a propriedade sobre as coisas tem pouco campo para aplicação, é justamente a propriedade do conhecimento a marca distintiva entre os que têm (sabem) muito e os que têm (sabem) pouco. Essa diferença entre saber muito e pouco não é uma contingência, é algo construído com o tempo, e funciona como um motor essencial da estrutura de poder nessas sociedades (SÁEZ, 2001).

Os alunos Kaiowá/Guarani informam sobre a existência de especialistas em suas comunidades. Segundo eles, há pessoas detentoras de certos conhecimentos que são inacessíveis a outros índios: "para nós, indios, somente o cacique tem explicacões para certas coisas que ninguém consegue explicar; doenças, principalmente, primeiro de tudo a gente procura o cacique; nós temos o cacique, um grande homem, ele explica a nossa ciência tradicional". Reconhecem, também, que há conhecimentos exclusivos de outros segmentos da comunidade, diferentes do cacique: "tem os que sabem conhecimentos especificos: as parteiras, por exemplo, a sua sabedoria é muito rica, só ela sabe orientar na hora da mulher e fazer remédio"; "meninas, tem coisas que só aprende com as mães, homem não pode saber, nem os pais; é a mesma coisa os meninos". Há, ainda, conhecimentos necessariamente partilhados pelo grupo, como os relativos à sobrevivência material: "cada um pode ter conbecimento que todos sabem, a época certa da plantação, [por exemplo], mas cada um precisa descobrir as coisas certas, muitas vezes precisa descobrir algo novo para viver, solução para vida melhor; aí passa o ensinamento para as pessoas da comunidade".

A fala de Otoniel Benites (destacada no início desta seção) expressa um aspecto distintivo da transmissão do conhecimento tradicional: um processo que se dá "oralmente, passado pela família". Como e quando isso ocorre? O conhecimento "é passado, na hora de dormir, na hora do chimarrão, do tereré", manhã ou noite" e "nenhum conbecimento é passado por acaso". A esse respeito, Eliézer Martins, ex-aluno do Projeto Ara Verá, fornece mais informações:

3 Tereré é um chá, preparado em uma cuia com água fria ou gelada e erva-mate moída. É um costume dos Kaiowá/Guarani que se espalhou por todo o estado de Mato Grosso do Sul. 
'[...] desde cedo a criança aprende com os pais o que deve fazer, se vai ajudar na roça, se acompanba o pai ou a mãe, como é a reza, os cantos, a cerimônia do milho, os remédios, como que deve comportar, como que deve falar com os não-indios [...], é assim pra nós, pode ser que é diferente em outro lugar, outro indio, Terena, no Amazonas, Xavante, mas pra nós é assim. Pra nós precisa ensinar, tendo um lugar próprio pra cada ensinamento: na mata, na roça, na casa, na hora de dar conselho, que os mais velhos chama. Tem coisa que não explica detalhado para as crianças, elas imitam, quando vê, já está fažendo igual [...]”.

A fala de Eliézer Martins reforça a importância da família no ensinamento das tradições ${ }^{4}$. Como se observa, cabe aos mais velhos a função de transmitir os conhecimentos aos mais novos. As crianças e os jovens aprendem ouvindo ou imitando os mais velhos. Convém destacar que essa transmissão não se dá de modo informal. Há exigência de lugares específicos para cada tipo de ensinamento. A mata e a roça são alguns deles.

Essa informação nos leva a pensar na importância do ambiente natural como locus de ensinamento de práticas de sobrevivência, de lazer, de rituais e regras de convivência. Esse é um dado extremamente importante, pois coloca em relevo a necessidade da conservação ambiental, não só para a produção de conhecimentos relacionados à sobrevivência material dos povos tradicionais, mas também para a sua educação e formação moral e espiritual. É o ambiente natural o lugar apropriado para o aconselhamento, para o ensino da reza, dos cantos, dos remédios, dos mitos, das regras do uso da mata, dos animais. A fala do cacique Jofre, em uma intervenção na aula de ciências naturais no Projeto Ara Verá, é contundente:

"É importante a mata, ali que vou caminhando e ensinando criança que tem dono a mata, cada árvore tem dono, aña para'i [dono], que cuida de cada uma planta; ouve o choro, o canto do mato, a conversa, é sagrado, vê planta que faz remédio, aroeirinha, alecrim, dono da aroeira é mais bravo; se acaba as matas, não tem mais história, não ensina mais [...]".

Até aqui foram exploradas algumas características do conhecimento tradicional. Vimos que é um conhecimento empírico, fruto de trabalho intelectual, transmitido oralmente de geração em geração, e aprendido no engajamento prático, ou obtido por revelações divinas. Não separa o mundo físico, do espiritual e social. Cada tipo de ensinamento exige lugares apropriados para a transmissão, e o ambiente natural é lugar privilegiado para a sua transmissão, reprodução e produção. Não há especialistas detentores da sua totalidade, pois os canais de distribuição são diversos, tornando-o fragmentado no seio da comunidade.

Uma outra característica desse conhecimento pode ser identificada na fala de Eliézer Martins: "é assim pra nós, pode ser que é diferente em outro lugar, outro indio, Terena, no Amazonas, Xavante, mas pra nós é assim". Pode-se depreender dessa fala que o conhecimento tradicional é local. Essa característica é discutida por alguns autores, segundo diferentes perspectivas.

\footnotetext{
${ }^{4}$ A família não é necessariamente do tipo nuclear, como conhecemos em nossa sociedade. Há, entre os Kaiowá/Guarani, a exemplo de outras sociedades tradicionais, um agrupamento familiar que denominamos de "família extensa", composta de diversos elos de parentesco ou de amizade.
} 
Para Ellen e Harris (1996), a expressão "local" remete a um conhecimento enraizado em um espaço particular e gerado por habitantes desse espaço, com base em suas experiências. Já para Gallois (2004), o "local" refere-se mais ao campo de aplicação do que ao de produção, isto é, ao lugar em que esse conhecimento é válido (na roça, na festa, na pesca, no canto, no modo de falar, vestir etc), e não à circunscrição a um espaço geográfico fechado. A autora explicita que essa condição não existe, visto que, entre as populações tradicionais, é comum haver intercâmbio. De fato, o intercâmbio de informações é mencionado entre os Kaiowá/Guarani. Avelino, índio Kaiowá/Guarani, antigo morador da Aldeia Te'ýikue em Caarapó, Mato Grosso do Sul, lembra que "muitos que vem do Paraguai sabem algumas coisas e ensina para mim; e nós sabe muitas coisas que aprende aqui na Aldeia, na cidade, com os parentes; e ensina pra eles, sempre assim $[. .$.$] ".$

Do que foi explorado até aqui, não se pode deixar de destacar a importância da manutenção das condições de produção para a continuidade da existência do conhecimento tradicional. A esse respeito, Cunha (1999) adverte: erodidas as condições, isto é, deterioradas as formas sociais, território, instituições que permitem experimentar, inovar e pesquisar, seriam seriamente atingidos os processos e, portanto, a natureza desses saberes. Os Kaiowá/ Guarani percebem, com clareza, a importância da terra como lugar de produção das tradições e de afirmação do seu modo de ser. Renata Castelão, ex-aluna da primeira turma do Projeto Ara Verá, afirma: "[...] na nossa história, perdemos aves, pássaros, mata, perdemos a terra, nosso chão, onde fortalece a nossa lingua, perdemos família e conhecimento; agora estamos recuperando". Em fala no I Seminário sobre Políticas de Sustentabilidade nas Terras Indígenas de Mato Grosso do Sul, promovido pela UCDB em 2005, Eliézer Martins destaca:

"Eu entrevistei o capitão da aldeia para ver o que ele pensava sobre porque se deve retomar a terra. Ele disse: a terra é o nosso chão, onde se brinca, dança, comemora, planta. É de muito valor o chão e o espaço. O chão que vai fortalecer a dança, a lingua... É um modo de ser; ali ele é praticado, nos momentos certos, repassar os conbecimentos pras crianças, ensinar pra elas que a terra épra sempre.. Não é que vale pra vender; não é pra vender."

Deixei para explorar no final desta seção uma característica inerente à tradição: a dinamicidade. Com isso, pretendo pensar, agora, na possibilidade de relações de troca entre culturas, como geradoras de transformações recíprocas e que, sob certas condições, podem contribuir para a continuidade da suas existências.

Sabemos que sociedades tradicionais interagem com outras populações (tradicionais ou não) e isso as induz a transformações no seu modo de vida. Para Gallois (2004), reconhecer a mutabilidade histórica como uma condição inerente à cultura possibilita abandonar a imagem negativa que suscita a idéia de perda de conhecimentos e favorece a operar com a idéia de avanço proporcionado pelas novas aquisições que, sem dúvida, transformam os conhecimentos tradicionais. A autora entende que a força do conhecimento tradicional reside, justamente, na sua capacidade de se adequar ao mundo atual. A esse respeito Cunha (1999) enfatiza: tanto quanto ou talvez mais do que informações, o que se transmite do conhecimento tradicional é uma combinação de pressupostos, formas de aprendizado, de pesquisa e de experimentação. Portanto, o que distingue um conhecimento como tradicional é, fundamentalmente, o modo, o processo, a forma como é adquirido, produzido, usado e transmitido, e não o seu conteúdo específico. 
"Conhecimento tradicional" e currículo multicultural...

Não se pode perder de vista, contudo, a possibilidade de as condições de mutabilidade e inovação atingirem os processos que regulam a autonomia e a liberdade de vivenciar o modo de ser das sociedades tradicionais. De qualquer modo, ninguém melhor do que elas para dizer quais inovações lhes interessam e como poderão ser absorvidas, re-configuradas, incorporadas e articuladas em favor do fortalecimento das suas identidades. Sobre isso, Renata Castelão, ex-aluna Kaiowá/Guarani do Projeto Ara Verá, faz algumas considerações: "sempre vai haver modificações por causa das pressões de fora da nossa cultura [...], mas as mudanças [...] não devem atingir a nossa identidade". E continua: "[...] vocês falam que nós não somos indios, mesmo porque nós usa celular, calca jeans, e outros até fica cantando música sertaneja: eu sou [índia] porque eu sinto que eu sou, porque eu penso como indio; não tem nada ver roupa, a casa de material; eu tenho dentro de mim essa força que é mesmo kaiowálguarani."

\section{Tensões relativas à pesquisa e à inclusão dos "conhecimentos tradicionais" nos currículos escolares: algumas aproximações}

O mundo é multicultural, no sentido que este termo refere-se a um território no qual coexistem grupos de origem étnica e geográfica diversas. Cada vez mais, a mobilidade populacional tem colocado em relevo a questão da interação entre grupos culturais distintos. Como já foi dito, as relações de intercâmbio entre culturas geram transformações recíprocas que podem ou não favorecer a continuidade da sua existência.

A convivência entre as diversas culturas é discutida por Mc Laren (2000), ao abordar as diferentes formas apresentadas pelo multiculturalismo: (1) multiculturalismo conservador de intolerância, deslegitimação dos saberes, línguas, crenças e valores do Outro; (2) humanista liberal - que afirma a igualdade intelectual dos diferentes grupos culturais e cria programas específicos de acesso e integração ao modelo social vigente; (3) liberal de esquerda - que enfatiza a diferença cultural, mas obscurece as condições de poder e a historicidade da construção das diferenças; (4) multiculturalismo crítico ou revolucionário - que entende as diferenças como representações, como produtos de lutas sobre signos e significados, e se compromete com a transformação dos contextos em que os significados e a injustiça social são gerados.

Para Candau (2005), a concepção de inteculturalismo, na perspectiva do multiculturalismo crítico discutido por Mc Laren (2000), pode se afirmar como uma resposta à questão da convivência entre a pluralidade de culturas. A autora, assim como Fleuri (2002), assinala que o interculturalismo concebe as diferenças culturais como produtos da história, de lutas sociais mais amplas sobre signos e significações, e tem como agenda política a transformação de relações sociais, culturais e institucionais.

Larrosa (2002, p. 137) entende que o encontro relacional entre a lógica autoritária da formação ocidental (que só permite olhar e ouvir "a partir do que sabe, do que quer e do que precisa") e a lógica silenciada só será possível quando aquela for questionada e estiver disposta "a ouvir o que não sabe, o que não quer, o que não precisa [...]" (p. 138).

Tomando como referência o multiculturalismo crítico de Mc Laren (2000), o interculturalismo, na perspectiva de Candau (2005) e Fleuri (2002), e a proposta de Larrosa (2002), farei algumas considerações sobre possibilidades de colocar a pesquisa e o ensino dos conhecimentos tradicionais nas agendas de respostas à convivência entre culturas distintas. Parto de uma compreensão de pesquisa e ensino como atividades situadas em uma dimensão relacio- 
nal, isto é, na intenção de encontrar o que cada uma das pessoas envolvidas nessas atividades oferece para a construção de relações entre sujeitos dispostos a se influenciar reciprocamente. Lançarei mão de outros autores e, também, das falas dos Kaiowá/Guarani para me auxiliarem nessa tarefa.

Não se pode negar que são inúmeros os desafios a enfrentar na construção de relações interculturais pela via da pesquisa acadêmica. A visão de mundo etnocêntrica e eurocêntrica do colonizador deixou-nos o legado da exploração e da espoliação. Vemos culturas diferentes como inferiores e, por conseguinte, negamos toda lógica e todo o conhecimento que não seja o nosso. Foi sob essa orientação que a academia fez, desde sempre, suas pesquisas sobre outras culturas, e não com outras culturas. Dessa forma, as pesquisas sobre outras culturas, ao contrário do que pensamos, acabam por nos dizer muito menos do que pensamos saber sobre elas.

A insistência em olhar o conhecimento tradicional com base nos paradigmas da academia pode redundar em pesquisas com resultados distorcidos, que deixam de fora informações valiosas por não estarem congruentes com o critério disciplinar e os parâmetros classificatórios acadêmicos (AGRAWAL, 2002, 1995). Essa prática impõe limitações que dificultam a percepção de conexões que confere validade a esse conhecimento e dentro das quais ele opera (ELLEN, HARRIS, 1996). Além do mais, o critério que orienta as escolhas do que deve ou não ser pesquisado, via de regra, atende a interesses econômico-materiais, o que não coaduna com a visão que as populações tradicionais têm do valor de seu conhecimento (SÁEZ, 2001; SAHLINS, 1997).

A fala de Otoniel Benites (destacada na seção anterior) denota uma preocupação que não só vai ao encontro dessas observações como aponta para outras questões relativas à pesquisa do conhecimento tradicional. Para ele, "a força do conbecimento tradicional é a oralidade; na escrita, ele se perde”. Elizabete Fernandes, ex-aluna do Projeto Ara Verá, desenvolve essa idéia:

"Perde o conhecimento oral quando fica preso na escrita, perde no tempo, no pedacinho que consegue registrar [...], hoje é um; amanhã é outro; não dá pra escrever tudo do jeito que é [...]. Uns sabe uma coisa, outro completa [...]. Na cabeça, no oral é que é a riqueza [...] Mas, se não escreve agora, os conhecimentos dos mais velhos vai se perder, não passou para os mais novos, é pouco aqueles que quis aprender [...]"

Essas falas nos dizem que o conhecimento tradicional resiste à pretensão de ser isolado em fragmentos escritos. A sua riqueza está "no oral", uma vez que a escrita implica, inexoravelmente, a "perda" dos significados atribuídos no contexto da produção e aplicação. Isso porque a escrita congela fragmentos do conhecimento que não expressam todo o vigor do seu dinamismo.

O aprisionamento desse conhecimento pela escrita levanta, pois, questões de ordem epistemológica. Ellen e Harris (1996), assim como Agrawal (2002), entendem que o deslocamento do conhecimento tradicional do seu campo de produção e operação, a fim de se tornar objeto de registro, implica, necessariamente, a perda de elementos essenciais que o caracterizam como tal - oralidade, localidade, validade contextual e dinâmica. De acordo com Agrawal (2002), para se tornar registro, o conhecimento tradicional passa por um processo de cientifização que confere a ele um caráter de permanência. Para Meliá (2004), os conhecimentos tradicionais - orais, contextualizados e localizados - não podem ser reconhecidos como tal quando são flagrados, como se fossem estáticos, para serem aprisionados e congelados na forma escrita. 
As questões epistemológicas relativas ao registro dos conhecimentos tradicionais dizem respeito não só à pesquisa, mas também ao ensino. Os currículos também aprisionam, descontextualizam e congelam os saberes, sejam eles tradicionais ou não.

Diante dessas considerações, seria conveniente, ou mesmo possível (do ponto de vista epistemológico) registrar os conhecimentos tradicionais? A quem caberia essa tarefa? A quem interessa o conhecimento registrado? Como lidar, tanto no ensino como na pesquisa, com a tensão entre registro/perda, oralidade/riqueza dos conhecimentos tradicionais? Como tornar a pesquisa e o ensino instrumentos de construção de relações interculturais?

As argumentações apresentadas até aqui, com foco nas restrições epistemológicas, levam a crer na impossibilidade de registro do conhecimento tradicional tout court. Contudo, ainda que isso seja verdade e se admita a perda da riqueza ou a descaracterização do conhecimento tradicional, quando aprisionado pela escrita, importa problematizar e levantar alternativas para a continuidade dessa discussão.

É sabido que as sociedades tradicionais reivindicam, cada vez mais, a documentação de seus saberes, pois concebem essa prática como uma estratégia importante para a sua salvaguarda e perpetuação. A fala da aluna Elizabete, mencionada anteriormente, destaca essa preocupação: "se não escreve agora, os conhecimentos dos mais velhos vai se perder, não passou para os mais novos, é pouco aqueles que quis aprender". Essa mesma posição pode ser vista na Carta de São Luís (2001), documento produzido por representantes dos povos indígenas do Brasil, no qual reivindicam o reconhecimento dos "conhecimentos tradicionais como saber e ciência", além da criação de "um banco de dados e registros sobre os conhecimentos tradicionais" de forma a protegê-los e a favorecer a "distribuição eqüitativa de benefícios resultantes destes recursos e conhecimentos".

Posey (1997), Little (2002) e Agrawal (2002) sugerem pensar em algumas possibilidades de fortalecimento das culturas historicamente subordinadas pela via da pesquisa/registro dos seus saberes. Posey (1997) acredita que a superação do caráter meramente extrativo e espoliador das pesquisas sobre os conhecimentos tradicionais depende, fundamentalmente, da compreensão, pelos pesquisadores acadêmicos, de que são os contextos (de aquisição, reprodução e transmissão) dos conhecimentos tradicionais que lhes conferem os significados. Assim, a pesquisa deve captar ao máximo esses contextos. O autor reconhece, todavia, que isso é mais fácil exigir do que oferecer, e, por isso, não espera que o pesquisador consiga descrever os conhecimentos tradicionais na sua complexa trama de variações. Porém, considera que é preciso exigir dele um esforço para a obtenção de informações a partir de diferentes membros do grupo, além da capacidade de identificar e medir a variedade de saberes e práticas, de tipologias de seus detentores (especialistas, pessoas comuns), suas esferas de ação e sua dinamicidade histórica. Little (2002) propõe experiências de colocar, lado a lado, pesquisadores acadêmicos e povos tradicionais, dispostos a compreender as lógicas e estruturas internas de ambas as culturas. Nessa experiência, ambos os pesquisadores devem ser capacitados para conhecer um ao/do outro, especialmente as suas cosmologias, a organização social, as lógicas que sustentam os conhecimentos e as tecnologias que produzem. Agrawal (2002) ressalta que, quaisquer que sejam as formas encontradas para a salvaguarda e empoderamento dessas populações, a pesquisa e a documentação dos conhecimentos tradicionais serão somente uma das muitas ações a serem desenvolvidas. $\mathrm{O}$ autor sugere, além da pesquisa, ações que permitam exercer maior pressão sobre os governos, questionar a ciência, apoiar iniciativas e processos decisórios dos povos tradicionais.

No conjunto dessas ações, penso que merece especial atenção a construção de currrí- 
culos pluriculturais para as escolas indígenas e não-indígenas. $\mathrm{O}$ reconhecimento do caráter social e cultural dos currículos permite, de acordo com Silva (2004), colocar os conhecimentos tradicionais e os científicos lado a lado, uma vez que ambos passam a ser vistos como objetos culturais, que expressam significados social e culturalmente construídos, buscam influenciar pessoas, estão envolvidos em relações de poder e produzem identidades. Quando concebidos dentro de um projeto deliberado de promoção do diálogo intercultural, os currículos funcionam como instrumentos de luta pela legitimidade de expressão de distintas culturas.

Mas, é preciso ter em mente que, no jogo das relações de poder, a promoção da interculturalidade exige que os currículos estejam comprometidos com os grupos culturais silenciados historicamente. Em outras palavras, conforme Candau (2005) e Fleuri (2002), a perspectiva intercultural na escola aspira a relação entre pessoas, mas uma relação de respeito e de escuta de outra identidade cultural, o que implica, dentre outros desafios, a abertura do currículo escolar a conhecimentos provenientes de lógicas distintas do conhecimento hegemônico do ocidente. Essa relação deve ocorrer em uma via de mão dupla, na qual um grupo se dispõe a influenciar o outro e, também, a deixar-se influenciar por ele.

Tal como foi pensado em relação à pesquisa, a construção do diálogo entre mundos diferentes, pela via do currículo da escola, é mais fácil de exigir do que oferecer. Mas, não se pode deixar de apostar nessa possibilidade, desde que as sociedades historicamente excluídas sejam chamadas a participar dessa construção. São elas que têm autoridade para dizer por que, para que, o que, como e quais são os conhecimentos que podem e/ou devem compor o currículo escolar.

\section{Considerações finais}

Se colocado a serviço da construção da interculturalidade, o currículo aberto a novas culturas deve ir além da simples inclusão de fragmentos do conhecimento de outras culturas nos conteúdos escolares. Paralelamente a isso, uma agenda voltada para a construção de contextos de relações interculturais inclui, dentre outros desafios, a criação de condições para que a escola discuta a história, a epistemologia e as relações de poder que envolvem os diferentes tipos de conhecimentos. Há que se pensar, também, em práticas pedagógicas renovadas, culturalmente orientadas, que respeitem as diferenças, as lógicas e os estilos de aprendizagem de cada cultura, e que estejam comprometidas com a elaboração de projetos coletivos de empoderamento dos povos culturalmente subordinados.

Experiências nesse sentido estão sendo desenvolvidas por professores Kaiowá/Guarani de Mato Grosso do Sul, juntamente com professores e pesquisadores de Instituições de Ensino Superior. Certamente, os Kaiowá/Guarani já têm algo a dizer sobre as possibilidades e dificuldades enfrentadas na construção dos projetos pedagógicos de suas escolas e na operacionalização de currículos que incluem a pesquisa e o ensino dos conhecimentos tradicionais. Eles podem nos mostrar como experimentam metodologias sustentadas no respeito e valorização de seus estilos de aprendizagem. Eles podem nos ensinar algo das experiências de um professor, que diz:

"O guarani/ kaiowá tem sua ciência, só que é diferente, não é igual a do branco. Os branco sabe que é nosso conbecimento, que é bom, tem valor [...] vem pesquisador saber. Só que o livro didático não mostra nada, não fala [...]. Hoje tenho esse compromisso de professor. Nós deve lutarpara ter livro didático com o conhecimento tradicional do guarani/ kaiowá, [os brancos] vai acreditar mais em nós; daqui algum tempo nosso conhe- 
"Conhecimento tradicional" e currículo multicultural...

cimento [vai] existir no livro dos branco também. Mas nossa luta tem que ser pra conseguir isso." (Anastácio Peralta, índio Kaiowá/Guarani, professor formado pelo Projeto Ara Verá)

\section{Referências}

AGRAWAL, A. El conocimiento indígena y la dimensión política de la clasificación.

Revista Internacional de ciencias sociales (El conocimiento indígena), Madrid, n. 173, p. 6-18, 2002.

Dismantling the divide between indigenous and western knowledge.

Development and Change, The Hague, v. 26, n. 3, p. 413-39, 1995.

BRAND, A. J. O impacto da perda das terras sobre a tradição Kaiowá/Guarani: os difíceis caminhos da palavra. 1997. 382f. Tese (Doutorado em História) - Pontifícia Universidade Católica do Rio Grande do Sul, PUC/RS, Porto Alegre, 1997.

CANDAU, V. M. Sociedade cultural e educação: tensões e desafios. In: Cultura(s)

e educação: entre o crítico e o pós-crítico. Rio de Janeiro: DP\&A, 2005. p. 13-38.

CARTA de São Luís do Maranhão, dezembro de 2001. Disponível em: <http:// www.biopirataria.org/artigos/Carta_Sao_Luis_do_Maranhao.pdf $>$. Acesso em: 12 ago. 2006.

CUNHA, M. C. Populações tradicionais e a Convenção da Diversidade Biológica. Estudos Avançados, São Paulo, v. 13, n. 36, p. 147-63, 1999.

DIEGUES, A. C. Etnoconservação da natureza: enfoques alternativos: In:

Etnoconservação: novos rumos para a proteção da natureza nos trópicos. São Paulo: HUCITEC, NUPAUB/USP, 2000. p. 1-46.

.; ARRUDA, R. S. V. (Orgs.). Saberes tradicionais e biodiversidade no Brasil.

Brasília: Ministério do Meio Ambiente; São Paulo: USP, 2001. (Biodiversidade 4).

ELLEN, R.; HARRIS, H. Concepts of indigenous environmental knowledge in scientifc and development studies literature: a critical assessment. In: EAST-WEST

ENVIRONMENTAL LINKAGES NET WORKSHOP, 3., 1996, Canterbury.

Proceedings... Canterbury, 1996.

FLEURI, R. M. Multiculturalismo e interculturalismo nos processos educativos. In:

CANDAU, V. M. (Org.). Ensinar e aprender: sujeitos, saberes e pesquisa. 2. ed. Rio de Janeiro: DP\&A, 2002. p. 67-82.

GALLOIS, D. T. O conhecimento tradicional. 28 maio. 2004. Notas de aula.

GRÜNBERG, F. P. Reflexões sobre a situação dos Guarani no Mato Grosso do Sul, Brasil. 2002. Digitado.

LÉVI-STRAUSS, C. O pensamento selvagem. Campinas: Papirus, 1989.

LARROSA, J. Notas sobre a experiência e o saber da experiência. Revista Brasileira de

Educação, Rio de Janeiro, n. 19, p. 20-8, 2002. 
Perrelli, M. A. S.

LITTLE, P. E. Etnoecologia e direito dos povos: elementos de uma nova ação indigenista. In: LIMA, A. C. S.; BARROSO-HOFFMANN, M. (Orgs.). Etnodesenvolvimento e políticas públicas. Rio de Janeiro: Contra Capa Livraria/LACED, 2002. p. 39-48.

Mc LAREN, P. Multiculturalismo revolucionário: pedagogia do dissenso para o novo milênio. Porto Alegre: Artes Médicas, 2000.

MELIÁ, B. Educação indígena e educação escolar indígena. 10-12 nov., 2004. Notas de aula.

MOREIRA, T. C. Proteção dos conhecimentos tradicionais: aspectos teóricos e jurídicos. Palestra, 2004. Disponível em: <http://www.redenortebrasil.org.br/doc/curso/ conhecimentos\%20tradicionais.ppt\#3>. Acesso em: 12 out. 2006.

POSEY, D. A. National laws and international agreements affecting indigenous and local knowledge: conflict or conciliation? APFT Working Paper 1, september, 1997.

Disponível em: < http://lucy.kent.ac.uk/Rainforest/SML_files/Posey/posey_TOC.html>. Acesso em: 16 ago. 2006.

ROUÉ, M. Novas perspectivas em etnoecologia: “saberes tradicionais" e gestão dos recursos naturais. In: DIEGUES, A. C. Etnoconservação: novos rumos para a proteção da natureza nos trópicos. São Paulo: HUCITEC, NUPAUB-USP, 2000. p. 67-80.

SÁEZ, O. C. Prometeo de pie: alternativas étnicas y éticas a la apropriacioón del conocimento. Ensayos e Investigaciones-Cuadernos de Bioetica, Buenos Aires, p. 1-15, 2001. Disponível em: <http://www. bioetica.org/cuadernos/enscons17.htm>. Acesso em: 28 ago. 2004.

Ciência amazonica: notas para um estudio critico de los saberes nativos. Soma Interazioni Terapeutiche e Antropologia Medica, Genova, v. 3, p. 1-7, 1998.

SAHLINS, M. O pessimismo sentimental e a experiência etnográfica: por que a cultura não é um objeto em via de extinção. Mana, Rio de Janeiro, v. 3, n. 1, p. 41-73, 1997.

SILVA, T. T. Documentos de identidade: uma introdução às teorias do currículo. 2. ed. Belo Horizonte: Autêntica, 2004.

Artigo recebido em dezembro de 2007 e aprovado em agosto de 2008. 